\title{
Current Source Back to Back Converter for Wind Energy Conversion Systems
}

\author{
I. Abdelsalam, G.P. Adam, and B.W. Williams
}

\begin{abstract}
This paper proposes a new back-to-back current source converter (BTB-CSC) suitable for mediumvoltage high power wind energy conversion systems (WECS). It employs a dual three-phase permanent magnet synchronous generator and two current source inverters with a phase-shift transformer at the grid side. The proposed BTB-CSC has the following advantages: reduced power circuit and control complexity; low switching losses (zero switching losses at the inverter side); and independent control of active and reactive power. PSCAD/EMTDC simulations are used as to assess the steady-state and dynamic behaviour of the proposed system under different operating conditions. It is shown that the proposed WECS can ride-through ac faults. Experimental results from scaled prototype of the proposed WECS are used to validate the simulations.
\end{abstract}

\section{Introduction}

Variable speed wind turbine systems are used to increase the kilowatt-hour production of wind turbine generators and their efficiencies and to reduce mechanical stresses on the drive train[1]. The doubly fed induction generator (DFIG) with a fractionally rated frequency converter between the grid and its rotor windings; and permanent magnet synchronous generators (PMSG) with a fully rated BTB converter are commonly used in variable speed WECSs. The use of permanent magnets (PMSG) is attractive because it reduces generator weight and increases reliability due to the absence of slip rings and brushes. The drive train technology for variable-speed synchronous generator based WECS can be classified to: direct drive train, Medium speed drive-train, and High speed drive-train[2, 3].

The PMSG output voltage and frequency vary with generator speed; therefore, the generator side converter must be able to operate at variable input ac voltage and frequency. Full scale BTB power converters are used to produce a constant frequency and voltage to meet load or grid requirements. Early generation multi-megawatt conventional variable speed WECS used BTB two level voltage source converters (VSC) [4-7]. A cheaper alternative being suggested for low power ratings employs WECS that consists of a diode rectifier at the generator side, a boost chopper as an intermediate stage to perform maximum power tracking, and a PWM VSC at the grid side $[8,9]$. In some cases, the BTB VSC is realized by Z-source inverters [10]; where the generatorside converter is a three-switch buck-type rectifier and the grid-side is a Z-source inverter. The use of high voltage may require series connection of switching devices, with voltage sharing. Some practical BTB VSC for 
WECS employ a multilevel neutral-point-clamped converter to reduce the voltage stress on the power switches and bulky ac filters at the grid side $[11,12]$.

With the use of multiphase machines, rated power of wind generators could be increased, and additional advantages can be obtained, such as reduced pulsating torque and current per-phase compared with three-phase of a similar rated power, lower the dc-link current harmonics, and higher reliability, with the possibility of fault tolerant operation [13-16]. A comparison between the three-phase PMSG and the dual three-phase based PMSG in WECSs presented in $[13,14,16]$ showed that the proposed WECS reduces the pulsating torque and the dc current ripple by $(30 \% \sim 40 \%)$, efficiency increased by 3\%, reduced dc-link inductance, and much higher dcvoltage can be produced from the dual diode rectifier (which means lower boost converter losses).

Reference [17] proposed a frontend converter for variable speed WECS that uses a dual three-phase PMSG with a dual parallel voltage source rectifier (VSR), where the rotor speed is estimated from the generator output voltage. The main limitation of this approach is that it does alleviate the problem of high-voltage stresses being exerted on the machine winding due switching of the VSR. Instead of parallel connection of VSR, [18] connected the two VSRs of the frontend converter in series to halve the voltage stresses on the winding of the six-phase generator. Although this approach is suitable for multi-MW application, it requires a complex control strategy to cope with variable frequency operation, and a number of self-commutated switches. The authors in [19] presented a reduced switch count WECS by using two half-controlled ac-dc converters to interface with the dual three-phase PMSG. This solution is attractive as it reduces the converter cost and losses by replacing six composite switches (IGBT plus anti-parallel diode) with six diodes. Despite the modification introduced to the power circuit, the authors show that this proposed dual half control converter can control both active and reactive power, with no torque ripple provided the sum of the generator currents of each phase is sinusoidal. An alternative solution based on full scaled BTB dual CSC WECS is proposed in [20], which operates at a low switching frequency $(350 \mathrm{~Hz})$. The heavy components such as a grid-side transformer and dc-link inductance can be placed at the bottom of the wind turbine tower for ease of installation and access. However, the use of a dual three-phase CSR increases the cost and control complexity of the generator side converter. Therefore, the alternative three-phase BTB CSC presented in $[21,22]$ is attractive as it reduces power circuit and control complexity. But it is not suitable for multi-MW variable speed WECSs due to using a three-phase uncontrolled diode rectifier, which cause high $5^{\text {th }}$ and the $7^{\text {th }}$ current harmonics in the generator side (high pulsating torque), and requires a large generator side C-filter capacitance. 
This paper introduces an improved version of the dual three-phase BTB CSC based converter presented in [21] and explorers its application in WECS. The proposed WECS in Fig.1 (a) retains all the attributes of the WECS presented in [22], plus elimination of low frequency pulsating torque in the PMSG. Its operation and control is detailed and is substantiated using PSCAD/EMTDC simulation and experimentation on scaled prototype. Performance of the proposed WECS during LVRT is examined using simulation.

\section{Proposed WECS}

\section{a. Proposal WECS Description and Modes of Operation}

Fig. 1(a) shows the proposed WECS that consists of a wind turbine with its medium-speed drive train and dual three-phase PMSG, with its generator-side C-filters $\left(C_{g}\right)$ connected to the inputs of the proposed BTB current source converter. The outputs of the proposed BTB converter are grid connected through C-filters $\left(C_{f}\right)$ and a three-winding phase-shift transformer. The proposal BTB converter has two operating modes, depending on the state of the active switch $S_{r}$. The first mode is when switch $S_{r}$ is on (the dc-side inductor $L_{d c}$ energized); the dclink inductance current $I_{L}$ rises. In this mode, $I_{L}$ is equal to the switch $S_{r}$ current $I_{s}$, which is drawn from the dual three-phase PMSG through the two cascaded three-phase bridge rectifiers, with no current at the input of the dual CSI $\left(I_{i}=0\right)$. The second mode starts when switch $S_{r}$ turns off (dc-link inductance de-energised), with dc-side inductor current $\mathrm{I}_{\mathrm{L}}$ falling and equal to input current of the dual CSI $\left(I_{\mathrm{i}}=I_{L}\right)$. During the second mode, the input currents of the generator side converter $i_{a b c r I}=i_{a b c r 2}=0$, and the generator side $\mathrm{C}$-filters $C_{g}$ are used for filtering and short duration temporary energy storage. Similarly, when $I_{i}=0$ in the first mode, the grid side C-filters $C_{f 1}$ are used for filtering to ensure that continuous sinusoidal currents are injected into grid.

With a medium voltage PMSG, the switch $S_{r}$ experiences high voltage stresses; thus requires series connection of several semiconductor switches. [23] proposed a solution to this issue, where the dc-side inductor was replaced by two equal inductors $\left(L_{d c l}=L_{d c 2}\right)$, then the voltage stress are equally shared by the two switches. Another solution is to use two independent sets of the three-phase BTB CSC as proposed in [21, 22] and shown in Fig. 1(b), where the high voltage stress is shared between switches $\left(S_{r 1}\right.$ and $\left.S_{r 2}\right)$ and the durability of the proposes WECS is increased, since in the case of half a generator winding failure or one converter set failure, the WECS can continue operating at half rating, with minimum interruption.

Switches $S_{r 1}$ and $S_{r 2}$ receive the same gating signal, and operation of the modified converters shown in Fig. 1(b) remains the same as the original version in Fig. 1(a). 


\section{b. Dual CSI Output Current Harmonics Cancellation.}

The proposed dual-bridge CSI in Fig. 1(a) injects power generated by the dual PMSG into the grid by modulating the dc-side inductor average current $\bar{I}_{L}$. This means that although instantaneous current at the input of the dual CSI $I_{i}$ is discontinuous, its average $\bar{I}_{i}$ over one fundamental period is constant. The dual CSI is switched at the fundamental frequency $50 \mathrm{~Hz}$, and the phase-shift transformer, cancels the $5^{\text {th }}, 7^{\text {th }}, 17^{\text {th }}, 19^{\text {th }}, 27^{\text {th }}$, $31^{s t}$, etc. harmonic currents component, while the inverter side C-filter has two functions: first it makes the dual CSI output current continuous, and second, removes the $11^{\text {th }}$ and $13^{\text {th }}$ harmonic components from the dual CSI output current. The phase output current of the dual-bridge CSI is shown in Fig. 1(c). To ensure zero switching losses at the dual CSI, the switching instants of the dual CSI devices must coincide with zero input dc link current $I_{i}=0$ (first mode), which is determined by the modulation of switch $S_{r}$. This requirement imposes the restriction that the ratio of the switching frequency of switch $S_{r}$ to the grid frequency must be an integer multiple of 3 (in other words, integer number of pulses per $120^{\circ}$ ) as discussed in $[21,22]$.

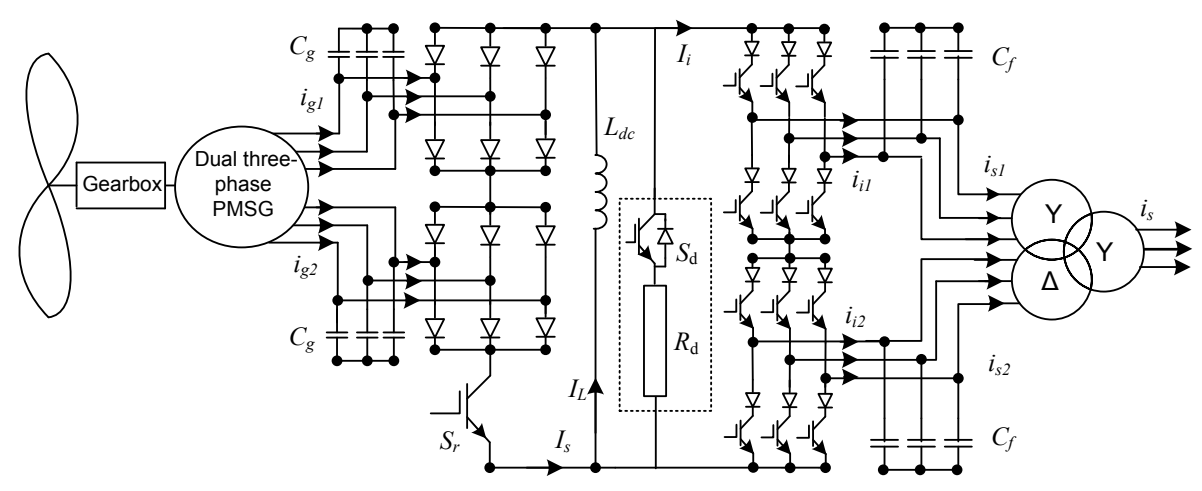

(a) Proposal WECS

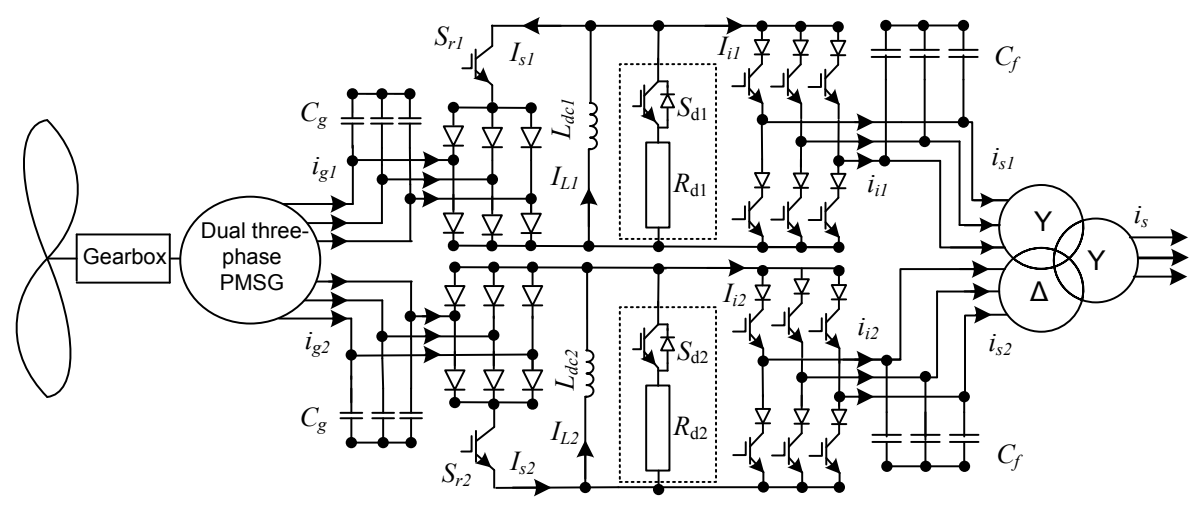

(b) Modified version of the proposal WECS 


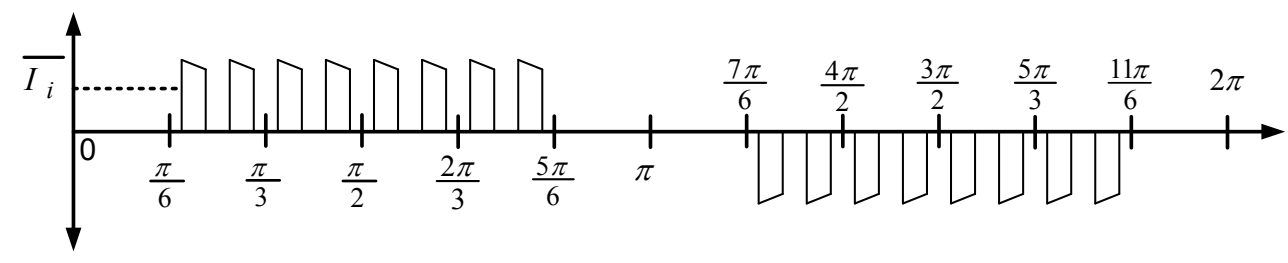

(c) CSI phase output current.

Fig. 1 Proposal WECS, modified versions, and CSI phase output current.

\section{c. Dual Three-Phase PMSG Model}

The dual three-phase PMSG being studied in this paper is comprised of two symmetrical sets of isolated threephase windings $a_{1} b_{1} c_{1}$ and $a_{2} b_{2} c_{2}$, shifted by $30^{\circ}[18]$. It is assumed that the stator windings are uniformly distributed and the magneto motive force is sinusoidal distributed in the generator air-gap, so that there are no higher order spatial harmonics. The generator is assumed to be round rotor or saliency is neglected by setting the direct and quadrature inductances equal $\left(L_{d}=L_{q}\right)$ [17]. The stator voltage $v_{g}$, current $i_{g}$ and flux $\psi$ are described by equations.

$$
\begin{aligned}
& {\left[v_{g}\right]=-[R]\left[i_{g}\right]-\frac{d}{d t}[\psi]} \\
& \psi=L i+\psi_{s f}
\end{aligned}
$$

where

$$
\begin{aligned}
& {\left[v_{g}\right]=\left[\begin{array}{llllll}
v_{a 1} & v_{b 1} & v_{c 1} & v_{a 2} & v_{b 2} & v_{c 2}
\end{array}\right]^{T}} \\
& {\left[i_{g}\right]=\left[\begin{array}{llllll}
i_{a 1} & i_{b 1} & i_{c 1} & i_{a 2} & i_{b 2} & i_{c 2}
\end{array}\right]^{T}} \\
& {[R]=r I_{6 \times 6}} \\
& \Psi: \quad \text { flux linkage } \\
& \Psi_{s f} \text { : permanent magnet rotor flux linkage } \\
& r: \quad \text { stator resistance }
\end{aligned}
$$

Representation of a dual three-phase PMSG in the $d q 0$ reference frame was described in [20]. The flux linkage matrix ,the generator voltage equation in the stationary $d q 0$ frame, the electrical rotor speed $\omega_{e}$, and electromagnetic torque $T_{e}$ are shown in equations (3), (4), (5), and (6) respectively. 


$$
\begin{aligned}
& {\left[\begin{array}{l}
\psi_{d 1} \\
\psi_{q 1} \\
\psi_{o 1} \\
\psi_{d 2} \\
\psi_{q 2} \\
\psi_{o 2}
\end{array}\right]=\left[\begin{array}{c}
L_{d} i_{d 1}+M_{s_{1} s_{2}} i_{d 2}+\sqrt{\frac{3}{2}} F_{c o u p} \\
L_{q} i_{q 1}-M_{s 1 s 2} i_{q 2} \\
L_{0} i_{01}-3 M_{s} i_{o 2} \\
L_{d} i_{d 2}+M_{s_{1} s_{2}} i_{d 1}+\sqrt{\frac{3}{2}} F_{c o u p} \\
L_{q} i_{q 2}-M_{s 1 s 2} i_{q 1} \\
L_{0} i_{02}-3 M_{s} i_{o 1}
\end{array}\right]} \\
& {\left[\begin{array}{c}
v_{g d_{1}} \\
v_{g q_{1}} \\
v_{g o_{1}} \\
v_{g d_{2}} \\
v_{g q_{2}} \\
v_{g 0_{2}}
\end{array}\right]=\left[\begin{array}{c}
-r i_{d 1}-p \psi_{d 1}+\omega_{e} \psi_{q 1} \\
-r i_{q 1}-p \psi_{q 1}-\omega_{e} \psi_{d 1} \\
-r i_{01}-p \psi_{01} \\
-r i_{d 2}-p \psi_{d 2}+\omega_{e} \psi_{q 2} \\
-r i_{q 2}-p \psi_{q 2}-\omega_{e} \psi_{d 2} \\
-r i_{02}-p \psi_{02}
\end{array}\right]} \\
& \omega_{e}=p_{n} \omega_{g} \begin{array}{c}
T_{e}=p_{n}\left(\psi_{d 1} i_{q 1}-\psi_{q 1} i_{d 1}+\psi_{d 2} i_{q 2}-\psi_{q 2} i_{d 2}\right)
\end{array}
\end{aligned}
$$

where

$F_{\text {coup }}$ : maximum magnetic coupling coefficient between rotor and stator

p: differential operator

$L_{d}: \quad$ direct-axis inductance

$L_{q}: \quad$ quadrature-axis inductance

$M_{s l s l}:$ mutual inductance coefficient

$\omega_{g}: \quad$ generator shaft speed, $\mathrm{rad} / \mathrm{s}$

$p_{n}: \quad$ number of pole pairs

\section{d. MMF produced by Harmonic Currents of Generator Side Converter}

The MMF produced by the generator current in the air gap is [24]:

$$
M M F=N i \sin \theta
$$

where $N$ : number of turns, $i_{g}$ stator current, and $\theta$ is the mechanical angle.

The analysis of the MMF produced by the generator side converter harmonic currents is carried out in two steps: First step: mathematically analyse the unwanted low frequency harmonics $\left(5^{\text {th }}\right.$ and $\left.7^{\text {th }}\right)$ generated as a consequence of the switching process of $S_{r}$. In [25] the three-phase ac-dc buck-boost rectifier input current spectrum was obtained using the double Fourier series in complex form, equation (8): 


$$
\begin{aligned}
& i_{r}(t)=\frac{2 \sqrt{3} \delta \bar{I}_{L}}{\pi} \sum_{n=1}^{\infty} \frac{1}{n} \sin n \omega_{0} t+\frac{4 \bar{I}_{L}}{3 \pi} \sum_{m=1}^{\infty} \frac{1}{m} \sin (\delta m \pi) \cos m \omega_{c} t \\
& +\frac{4 \bar{I}_{L}}{\pi^{2}} \sum_{m=1}^{\infty} \sum_{n=-\infty}^{\infty} \frac{1}{n m} \sin (\delta m \pi) \sin \left(\frac{1}{3} n \pi\right) e^{j \frac{1}{2} \pi(n+1)} \sin \left(m \omega_{c}+n \omega_{0}\right) t
\end{aligned}
$$

where: $\delta$ is the switch duty cycle such that $0 \leq \delta \leq 1, \overline{I_{L}}$ is the average dc-link inductance current, $m$ and $n$ are the orders of the carrier and baseband component harmonics respectively.

The first summation in equation (8) defines the fundamental low-frequency harmonics which include the loworder undesired harmonics. The second summation corresponds to the high-frequency carrier wave harmonics. The third summation refers to the sideband harmonics, which exist as groups around the carrier harmonic frequencies $[25,26]$. Equation (8) provides a theoretical solution for interpreting the ac harmonic distribution of the generator side converter, including basebands, carrier frequency, and sideband harmonics. The magnitudes of $5^{\text {th }}$ and $7^{\text {th }}$ harmonic currents of the first set of generator stator winding are expressed by substituting $n=5$ and 7 in the first term of equation (8), and a $30^{\circ}$ phase-shift is added for the second generator stator winding. Second step: calculate the resultant MMF of the $5^{\text {th }}$ and $7^{\text {th }}$ harmonic components in the air-gap. From equations (7) and (8) the MMF produced by $5^{\text {th }}$ harmonic current in the first generator stator winding set $\left(M M F_{(5,1)}\right)$ can be described as:

$$
\begin{gathered}
M M F_{(5,1)}=\frac{2 \sqrt{3} \delta \overline{I_{L}} N}{\pi} \frac{1}{5}\left(\begin{array}{l}
\sin 5 \omega_{0} t \sin \theta+\sin 5\left(\omega_{0} t-\frac{2 \pi}{3}\right) \sin \left(\theta-\frac{2 \pi}{3}\right) \\
+\sin 5\left(\omega_{0} t+\frac{2 \pi}{3}\right) \sin \left(\theta+\frac{2 \pi}{3}\right)
\end{array}\right)(9) \\
M M F_{(5,1)}=-\frac{2 \sqrt{3} \delta \overline{I_{L}} N}{5 \pi} \frac{3}{2} \cos \left(\theta+5 \omega_{0} \mathrm{t}\right)
\end{gathered}
$$

Similarly $M M F_{(7,1)}, M M F_{(5,2)}$ and $M M F_{(7,2)}$ :

$$
\begin{aligned}
& \operatorname{MMF}_{(7,1)}=\frac{2 \sqrt{3} \delta \bar{I}_{L} N}{7 \pi} \frac{3}{2} \cos \left(\theta-7 \omega_{0} \mathrm{t}\right) \\
& M M F_{(5,2)}=\frac{2 \sqrt{3} \delta \overline{I_{L}} N}{5 \pi} \frac{3}{2} \cos \left(\theta+5 \omega_{0} \mathrm{t}\right) \\
& M M F_{(7,2)}=-\frac{2 \sqrt{3} \delta \overline{I_{L}} N}{7 \pi} \frac{3}{2} \cos \left(\theta-7 \omega_{0} \mathrm{t}\right)
\end{aligned}
$$

Equations (14) and (15) show the resultant $M M F_{5}$ and $M M F_{7}$ respectively, and prove MMF cancellation. 


$$
\begin{aligned}
& M M F_{5}=M M F_{(5,1)}+M M F_{(5,2)}=0 \\
& M M F_{7}=M M F_{(7,1)}+M M F_{(7,2)}=0
\end{aligned}
$$

This means the first pulsating torque will be produced by the $11^{\text {th }}$ harmonic current, which can be removed by the generator side $\mathrm{C}$-filter.

\section{MPPT and grid reactive power controller}

Fig. 2(a) shows the MPPT control loop which is incorporated within wind turbine and drive train model, including the gear box ratio, and it calculates the corresponding optimal generator speed $\omega_{\text {opt }}$. A proportional integral (PI) controller is used to calculate the reference average inductor current $\left(\overline{I_{L_{-}} r e f}\right)$, from the speed controller that forces the generator actual speed to follow the optimal speed set by the MPPT controller; see Fig. 2(a). The inner loop is the current controller that regulates average inductor current $\left(\overline{I_{L}}\right)$ and generates the duty cycle for switches $S_{r l}$ and $S_{r 2}$.

The reactive power controller in Fig. 2(b) adjusts the phase angle $\alpha$ between the grid voltage and current dual CSI output current. Thus, $\alpha$ is added to angle $\omega t$, which is estimated from the phase locked loop (PLL), and the resultant angle $\omega t+\alpha$ is used as the time base for CSI1, and CSI2, however, the time based for CSI2 is modified to $\omega t+\alpha+\frac{\pi}{6}$ to compensate for the phase shift introduced by the transformer winding, see Fig. 2(b).

To establish the relationship between the grid delivered active/reactive power and the dc-link inductance average current $\bar{I}_{L}$ and the phase angle $\alpha$. Assuming the line-to-line voltage of all windings are equal: $\mathrm{v}_{\mathrm{p}}=\mathrm{v}_{\mathrm{s} 1}=\mathrm{v}_{\mathrm{s} 2}$, and the turn ratios of the transformer secondary and tertiary windings relative to primary are $\mathrm{N} 1 / \mathrm{N} 2=1$ and $\mathrm{N} 1 / \mathrm{N} 3=1 / \sqrt{3}$ respectively. Based on single line diagram shown in Fig. 2(c) the relation between the transformer primary and seconders currents are given in (16).

$$
i_{p}^{a b c}=i_{s 1}^{a b c}+i_{s 2}^{a b c}
$$

The relation between the two transformer secondary current $\left(i_{s 1}\right.$ and $\left.i_{s 2}\right)$ and dual CSI output current $\left(i_{i 1}\right.$ and $\left.i_{i 2}\right)$ and dual CSI filter capacitor current $\left(\mathrm{i}_{\mathrm{ci} 1}\right.$ and $\left.\mathrm{i}_{\mathrm{ci} 2}\right)$ are as following:

$$
\begin{aligned}
& i_{s 1}^{a b c}=i_{i 1}^{a b c}-i_{c 1}^{a b c} \\
& i_{s 2}^{a b c}=i_{i 2}^{a b c}-i_{c 2}^{a b c}
\end{aligned}
$$

With transformer primary leakage impedance is being referred to star connected secondary winding and delta connected tertiary winding $\left(L_{s 1}=L_{s}+L_{F}+L_{p}^{s}\right.$ and $L_{s 2}=L_{t}+L_{F}+L_{p}^{t}$ ), the dual CSI C-filter voltages ( $v_{c 1}^{a b c}$ and $v_{c 2}^{a b c}$ ), and currents $\left(i_{c 1}^{a b c}\right.$ and $i_{c 2}^{a b c}$ ) are expressed as:

$$
v_{c 1}^{a b c}=L_{s 1} \frac{d i_{s 1}^{a b c}}{d t}+v_{s 1}^{a b c}
$$




$$
\begin{gathered}
i_{c 1}^{a b c}=C_{F} \frac{d v_{c 1}^{a b c}}{d t} \\
v_{c 2}^{a b c}=L_{s 2} \frac{d i_{s 2}^{a b c}}{d t}+v_{s 2}^{a b c} \\
i_{c 2}^{a b c}=C_{F} \frac{d v_{c 2}^{a b c}}{d t}
\end{gathered}
$$

The steady state representation of the first set of dual CSI C-filter and current in the dq frame are:

$$
\begin{gathered}
v_{c d 1}=v_{s d 1}-\omega_{s} L_{s 1} i_{s q 1} \\
v_{c q 1}=v_{s q 1}+\omega_{s} L_{s 1} i_{s d 1} \\
i_{c d 1}=-\omega_{s} C_{F} v_{c q 1} \\
i_{c q 1}=\omega_{s} C_{F} v_{c d 1}
\end{gathered}
$$

Substituting equations (23) in (25) and (24) in (26) the dual CSI C-filter current can be expressed as following:

$$
\begin{gathered}
i_{c d 1}=-\omega_{s} C_{F}\left(v_{s q 1}+\omega_{s} L_{s 1} i_{s d 1}\right) \\
i_{c q 1}=\omega_{s} C_{F}\left(v_{s d 1}-\omega_{s} L_{s 1} i_{s q 1}\right)
\end{gathered}
$$

Substituting equations (27) and (28) in (17) to get the transformer seconders $i_{s 1}$ current in dq farm can express as following:

$$
\begin{aligned}
& i_{s d 1}=\frac{m_{d} \bar{I}_{i}+\omega_{s} C_{F} v_{s q 1}}{1+\omega_{s}^{2} C_{F} L_{s 1}} \\
& i_{s q 1}=\frac{m_{q} \bar{I}_{i}-\omega_{s} C_{F} v_{s d 1}}{1+\omega_{s}^{2} C_{F} L_{s 1}}
\end{aligned}
$$

Similarly, the dq currents at transformer tertiary winding are:

$$
\begin{aligned}
& i_{s d 2}=\frac{m_{d} \bar{I}_{i}+\omega_{s} C_{F} v_{s q 2}}{1+\omega_{s}^{2} C_{F} L_{s 2}} \\
& i_{s q 2}=\frac{m_{q} \bar{I}_{i}-\omega_{s} C_{F} v_{s d 2}}{1+\omega_{s}^{2} C_{F} L_{s 2}}
\end{aligned}
$$

Where $\bar{I}_{i}$ is the average dual CSI input current, $m_{d}=m \cos (\beta-\alpha)$ and $m_{q}=m \sin (\beta-\alpha)$ are $\mathrm{d}$ and q components of the modulating signals. Since the modulation index ' $m$ ' is fixed at ' 1 ' for simplicity, $m_{d}=\cos (\beta-\alpha)$ and $m_{q}=\cos (\beta-\alpha)$. This means both active and reactive powers are being controlled using $(\beta-\alpha)$. Recall that the relationship between the average dc current at the input of the dual CSI and the average dc-link inductance current $\bar{I}_{L}$ is:

$$
\overline{I_{i}}=(1-\delta) \overline{I_{L}}
$$

With assumption lossless interfacing transformer, the active and reactive power delivered to ac grid are:

$$
\begin{gathered}
P=v_{p d} i_{p d}=v_{s d 1} i_{s d 1}+v_{s d 2} i_{s d 2}+v_{s q 1} i_{s q 1}+v_{s q 2} i_{s q 2} \\
Q=-v_{p d} i_{p q}=v_{s q 1} i_{s d 1}-v_{s d 1} i_{s q 1}+v_{s q 2} i_{s d 2}-v_{s d 2} i_{s q 2}
\end{gathered}
$$


Fig. 2 (d) shows a phasor diagram of the upper current source converter in Fig. 2(c), and defines all direct and quadrature currents and voltages when the voltage vector at the primary side (point of coupling at grid side) is aligned with the d-axis. Fig. 2(c) and (b) and equations (29) to (35) show the relationships between the active and reactive powers delivered to the grid, average inductance current, power factor angle ' $\alpha$ ', and current and voltage load angles $\beta$ and $\delta$ respectively. In this paper, the maximum power point tracking (MPPT) controller depicted in Fig. 2(a) regulates the active power to be delivered to the grid as the wind speed varies. While the reactive power controller depicted in Fig. $2(b)$ is used to estimate the angle $(\beta-\alpha)$.

Furthermore, the effect of varying the average dc-link inductance current $\overline{\mathrm{I}}_{\mathrm{L}}$ and generator current $\mathrm{i}_{\mathrm{g}}$ is established, considering fundamental currents and voltages at the generator side. The rectifier input current is obtained as:

$$
\begin{aligned}
i_{r d 1} & =i_{g d 1}+\omega e C_{g} v_{g q 1} \\
i_{r q 1} & =i_{g q 1}-\omega_{e} C_{g} v_{g d 1} \\
i_{r d 2} & =i_{g d 2}+\omega e C_{g} v_{g q 2} \\
i_{r q 2} & =i_{g q 2}-\omega_{e} C_{g} v_{g d 2}
\end{aligned}
$$

The peak line fundamental current $\left(\mathrm{I}_{\mathrm{rp}}\right)$ at rectifier input is:

$$
I_{r p}=\sqrt{i_{r d 1}^{2}+i_{r q 1}^{2}}=\sqrt{i_{r 2 d}^{2}+i_{r 2 q}^{2}}
$$

The relation between the peak value of the rectifier input current and dc-link average inductance current $\overline{\mathrm{I}}_{\mathrm{L}}$ is [25]

$$
I_{r p}=\frac{2 \sqrt{3} \delta \overline{I_{L}}}{\pi}
$$

Substituting (41)in (40)

$$
\overline{I_{L}}=\frac{\pi}{2 \sqrt{3} \delta} \sqrt{i_{r 1 d}^{2}+i_{r 1 q}^{2}}=\frac{\pi}{2 \sqrt{3} \delta} \sqrt{i_{r 2 d}^{2}+i_{r 2 q}^{2}}
$$

From equation (42), the effect of adjusting the dc-side inductor current can be summarized as follows: when the wind turbine speed exceeds the optimal speed, the speed controller will increase the average current $\overline{I_{L}}$, which in turn increases the generator current to increase electromagnetic torque to slow down the turbine speed $\left(\omega_{g}\right)$, while at the same time the grid delivered power increases as discussed above. 


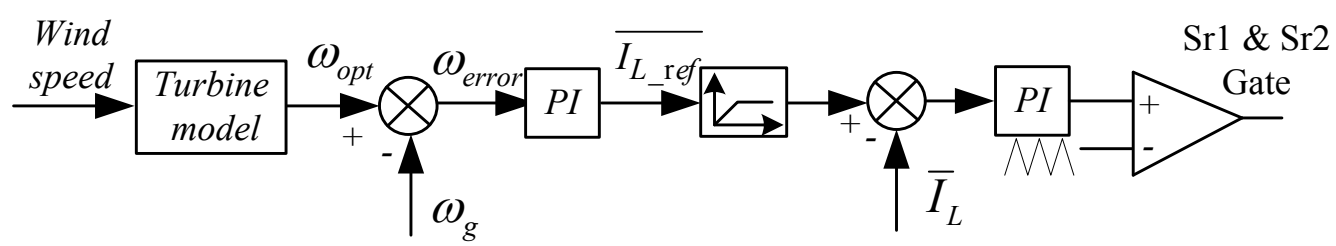

(a) MPPT control loop

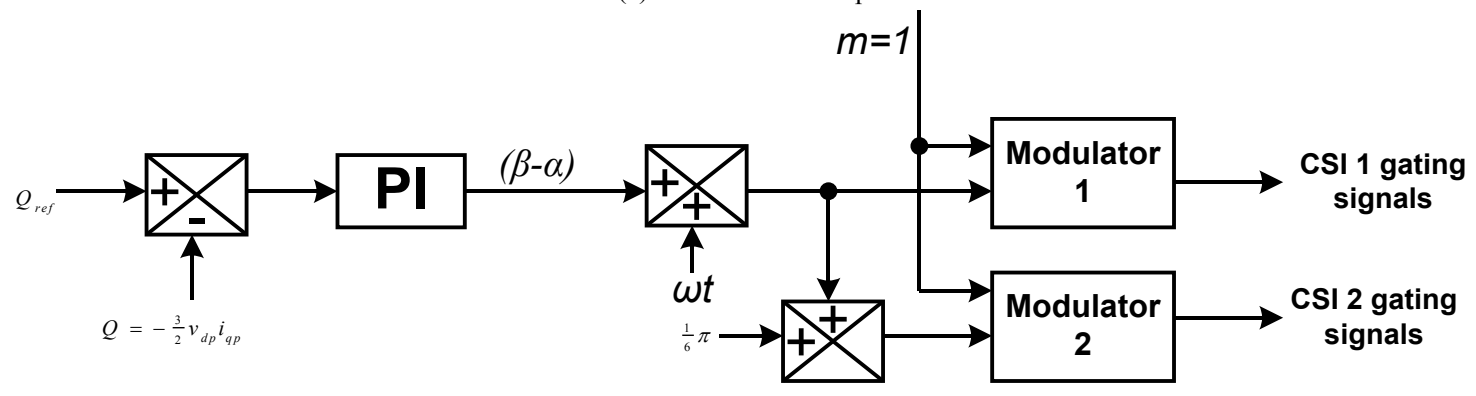

(b) Reactive power control loop

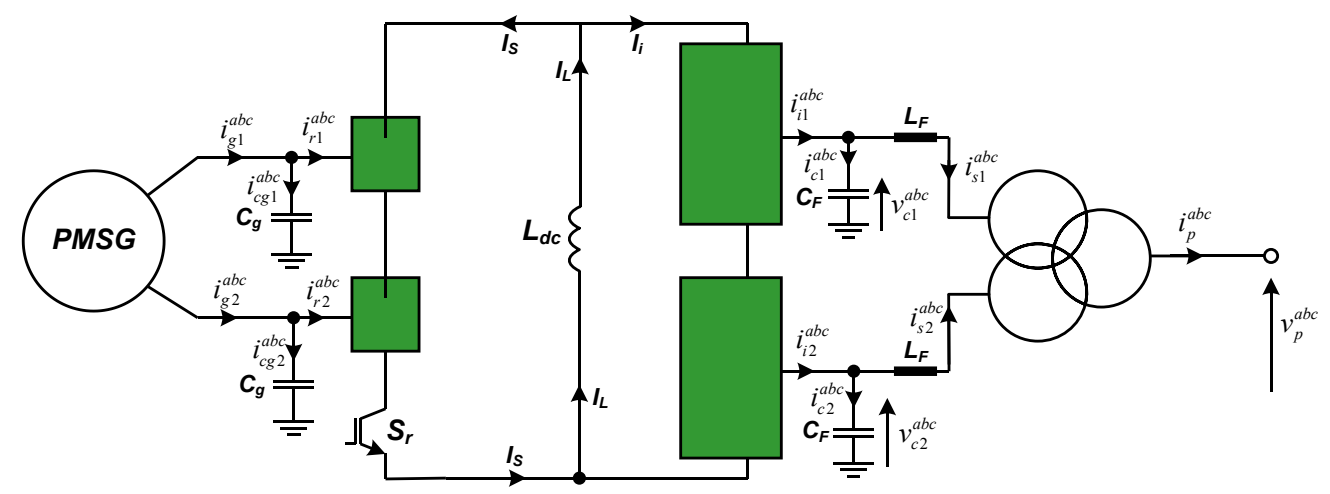

(c) Single line diagram of the proposed WECS

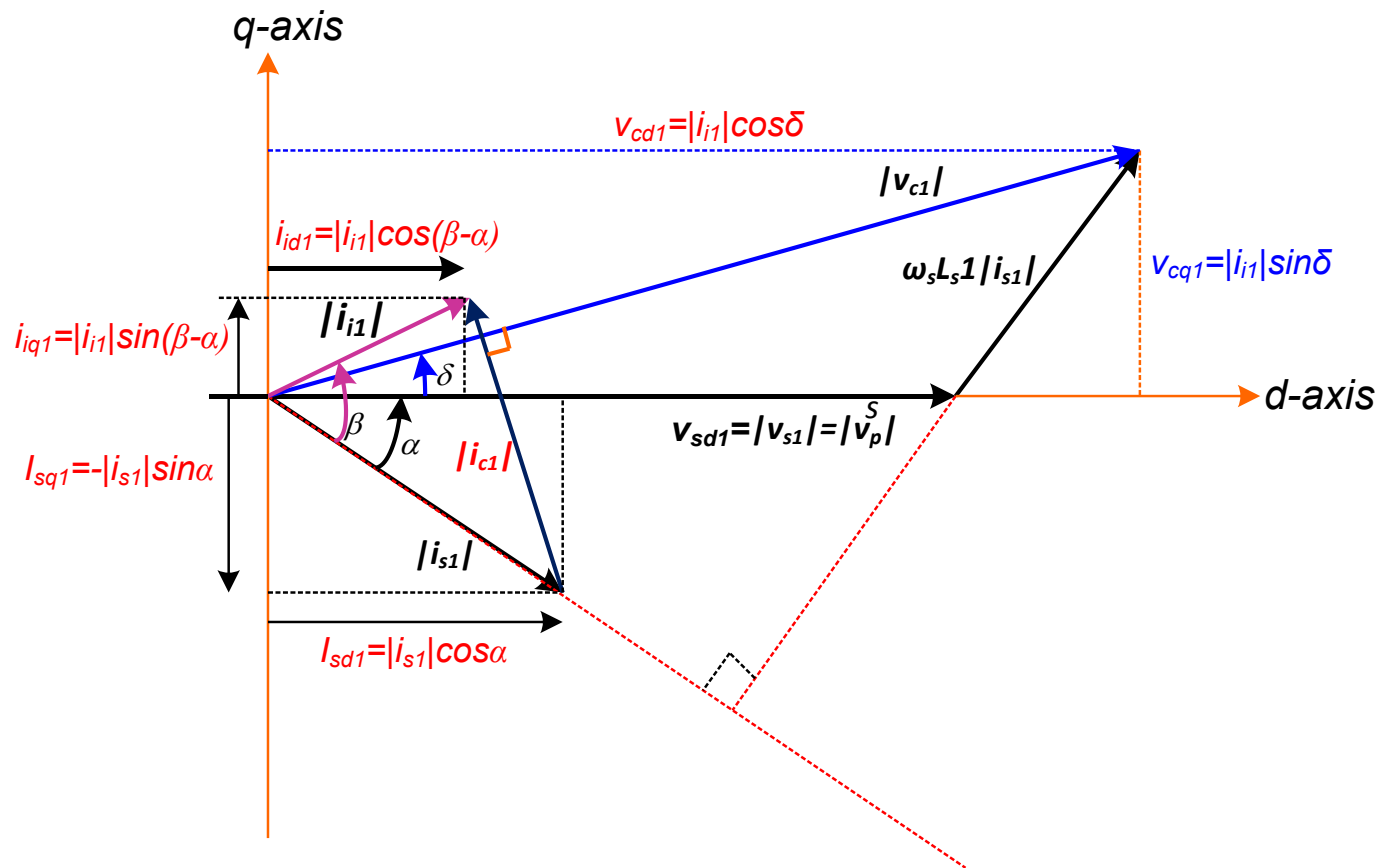

(d) Phasor diagram of the upper current source when all quantities are refer to secondary windings

Fig. 2 Proposed WECS control loops and WECS single line diagram representation 


\section{Simulation Results}

\section{a. Healthy operation}

The WECS in Fig. 1(b) is simulated using PSCAD/EMTDC. The simulation system parameters are shown in Table 1. To assess the steady state and dynamic performance of the proposed WECS, the system is simulated at several wind speeds, starting from $6.5 \mathrm{~m} / \mathrm{s}$ to rated wind speed, $12.5 \mathrm{~m} / \mathrm{s}$. Fig. 3 shows waveforms that illustrate the overall performance of the proposed WECS. Fig. 3 (a) shows that the proposed WECS tracks the optimal speed with minimum transients as the wind speed varies. Fig. 3(b) displays the changes in active power delivered into the grid by the dual CSI, as wind speed varies. Fig. 3(c) shows that the average dc-link inductor current increases with power delivered to the grid when the wind speed is increased from $10 \mathrm{~m} / \mathrm{s}$ to $12.5 \mathrm{~m} / \mathrm{s}$, with the current controller able to track $\left(\overline{I_{L_{-}} r e f}\right)$ with minimum transient. Fig. $4(\mathrm{a})$ and (b) show grid currents and phase ' $a$ ' voltage at $10 \mathrm{~m} / \mathrm{s}$ and $12.5 \mathrm{~m} / \mathrm{s}$ wind speeds, and observe that the proposal BTB converter delivers to the grid, sinusoidal current at near unity power factor. Fig. 4 (c) and (d) show the generator current of phases ' $a_{1}$ ' and ' $a_{2}$ ' at $10 \mathrm{~m} / \mathrm{s}$ and $12.5 \mathrm{~m} / \mathrm{s}$, which have different magnitude and frequency, as expected. Fig. 5 shows waveforms that analyse the converter performance. Fig. 5(a) shows the dc-link current, switch $\mathrm{S}_{\mathrm{r} 1}$ current and $\mathrm{CSI}_{1}$ input current $I_{i l}$, and observe that when the switch $S_{r l}$ is on, the dc-link inductance current builds up (charging mode), and when the switch $S_{r l}$ is off, the dc-link inductance current decreases and equals to the $\mathrm{CSI}_{1}$ input current $\mathrm{I}_{\mathrm{i} 1}$ (discharging mode). Fig. 5(b) and (c) show voltage stresses in the switches of the proposed WECS shown in Fig. 1(a) and of the modified version shown in Fig. 1(b) respectively/ Observe that the voltage stress in the switches of the modified version in Fig. 1(b) is half of the WECS in Fig. 1(a).

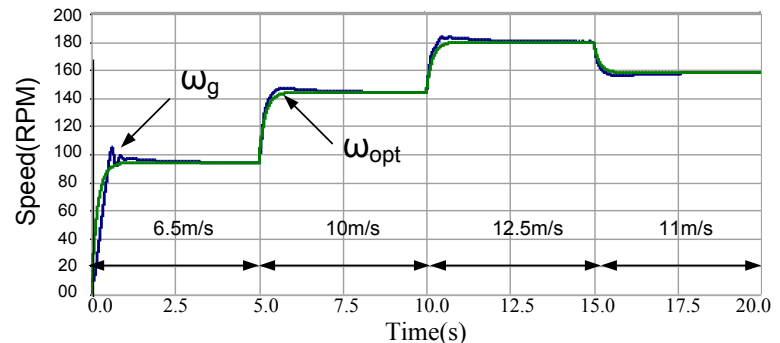

(a) Generator speed and optimal generator speed.

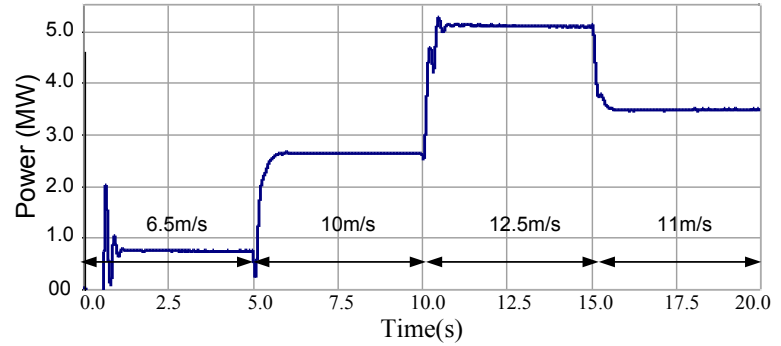

(b) Grid delivered power.

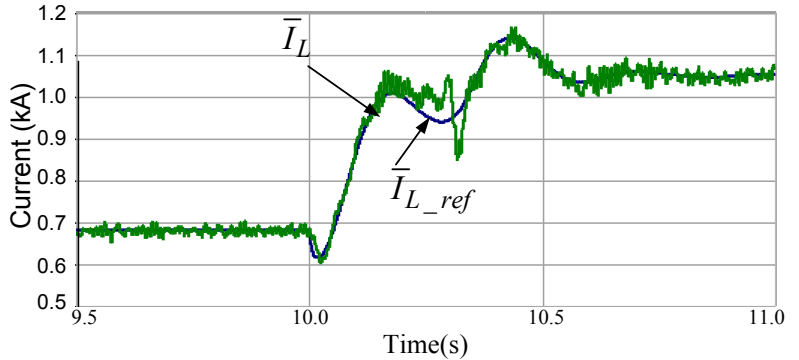

(c) Average dc-link inductor current during transient from Case 3 to Case 4. Fig. 3 PSCAD/EMTD simulation waveforms of the second WECS proposed. 
Table 1 The WECS PSCAD/EMTDC setup parameters

\begin{tabular}{|l|l|}
\hline \multicolumn{2}{|c|}{ Dual three-phase PMSG Parameters } \\
\hline Rated power & $5.2 \mathrm{MVA}$ \\
\hline Rated speed & $180 \mathrm{rpm}$ \\
\hline Rated voltage & $3.3 \mathrm{kV}$ \\
\hline Direct-axis inductance & $0.0055 \mathrm{H}$ \\
\hline Quadrature-axis inductance & $0.0055 \mathrm{H}$ \\
\hline Mutual inductance coefficient & $0.001 \mathrm{H}$ \\
\hline Number of poles & 34 \\
\hline Permanent magnetic flux & $14 \mathrm{~Wb}$ \\
\hline \multicolumn{2}{|c|}{ Wind Turbine Parameters } \\
\hline Rated power & $5.2 \mathrm{MW}$ \\
\hline Cut-in wind speed & $4 \mathrm{~m} / \mathrm{s}$ \\
\hline Rated wind speed & $12.5 \mathrm{~m} / \mathrm{s}$ \\
\hline Cut-out wind speed & $25 \mathrm{~m} / \mathrm{s}$ \\
\hline Rotor diameter & $108 \mathrm{~m}$ \\
\hline Rotor area & $9160 \mathrm{~m}$ \\
\hline Gearbox ratio & $1: 10$ \\
\hline \multicolumn{2}{|c|}{ Converter Parameters } \\
\hline Genrator side C-filter (Y connection) & $180 \mu \mathrm{F}$ \\
\hline DC side inductance & $5 \mathrm{mH}$ \\
\hline Grid side C-filter $(\Delta$ connection) & $55 \mu \mathrm{F}$ \\
\hline Phase-shifted transformer rated power & $5.2 \mathrm{MVA}$ \\
\hline Phase-shifted transformer rated voltage & $3.3 \mathrm{kV}$ \\
\hline Switch Sr frequency & $1.2 \mathrm{kHz}$ \\
\hline Converter rated active power & $5.5 \mathrm{MW}$ \\
\hline Converter rated reactive power & $3 \mathrm{MVAr}$ \\
\hline \multicolumn{2}{|c|}{} \\
\hline \multicolumn{2}{|c|}{} \\
\hline
\end{tabular}

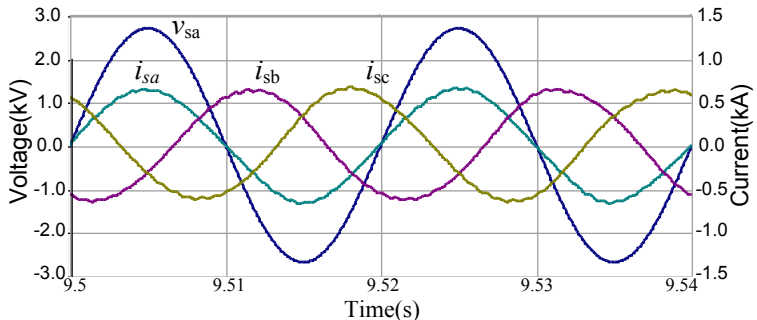

(a) Three phase grid currents and phase ' $a$ ' voltage at $10 \mathrm{~m} / \mathrm{s}$ wind speed

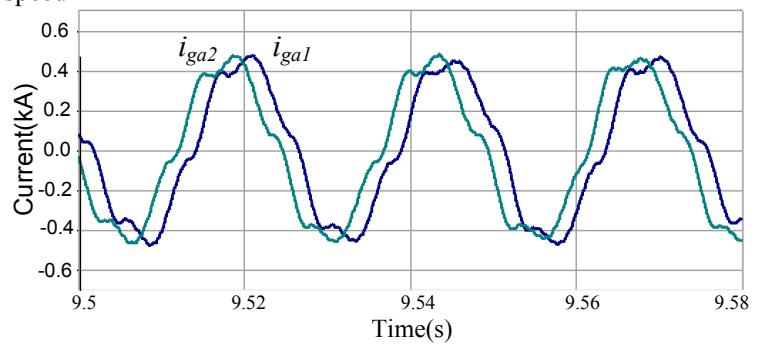

(c) Generator current of phases ' $a 1$ ' and ' $a 2$ ' at $10 \mathrm{~m} / \mathrm{s}$

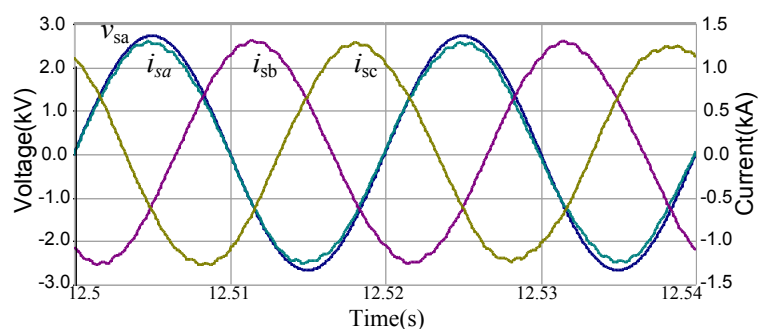

(b) Three phase grid currents and phase ' $a$ ' voltage at $12.5 \mathrm{~m} / \mathrm{s}$ wind speed

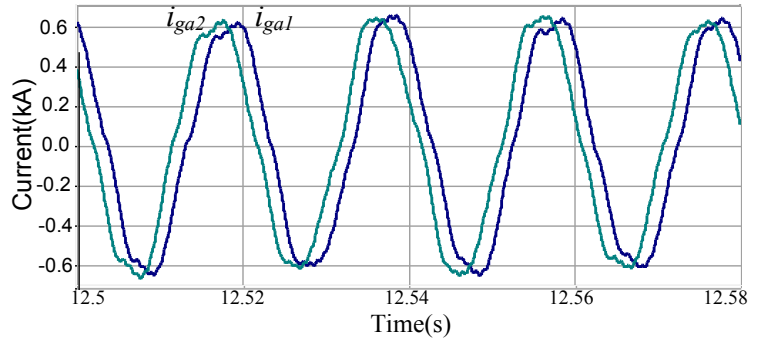

(d) Generator current of phases ' $a 1$ ' and ' $a 2$ ' at $12.5 \mathrm{~m} / \mathrm{s}$

Fig. 4 Simulation waveforms of the grid phase ' $a$ ' voltage and three-phase grid current at $10 \mathrm{~m} / \mathrm{s}$ and $12.5 \mathrm{~m} / \mathrm{s}$ wind speeds, and generator currents at $10 \mathrm{~m} / \mathrm{s}$ and $12.5 \mathrm{~m} / \mathrm{s}$ wind speeds. 


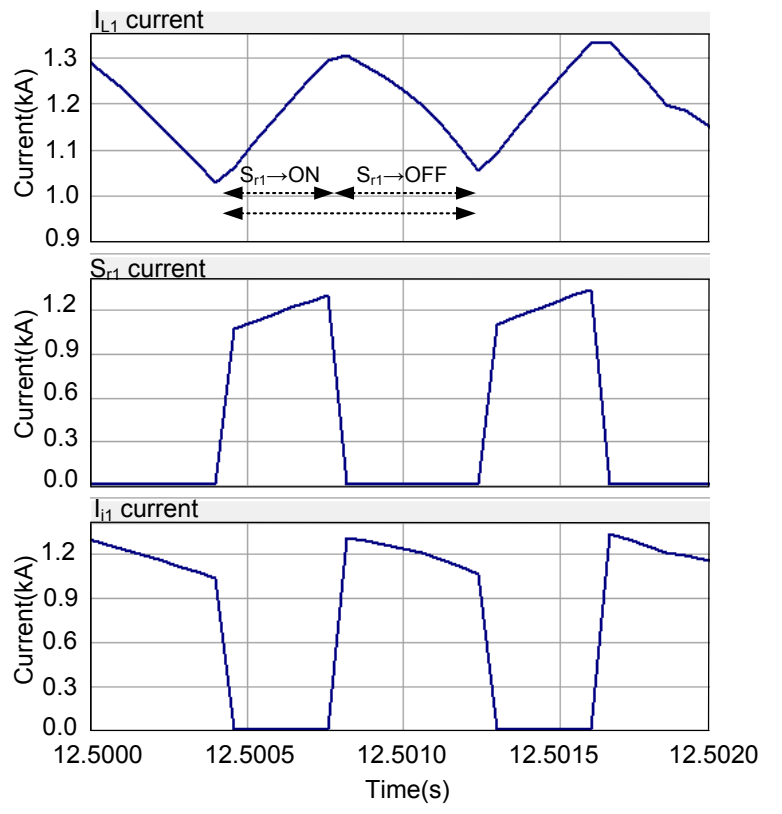

(a) Currents in the dc-link inductance $I_{L}$, switch $\mathrm{S}_{\mathrm{r} 1}$ and at the input of the CSI1 $I_{i 1}$

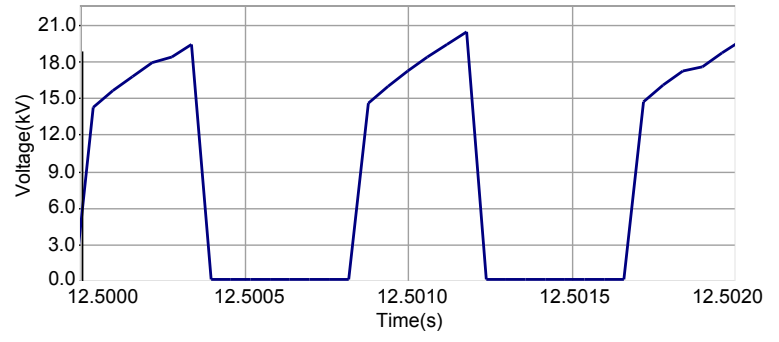

(b) Voltage stress across the switch $\mathrm{S}_{\mathrm{r}}$

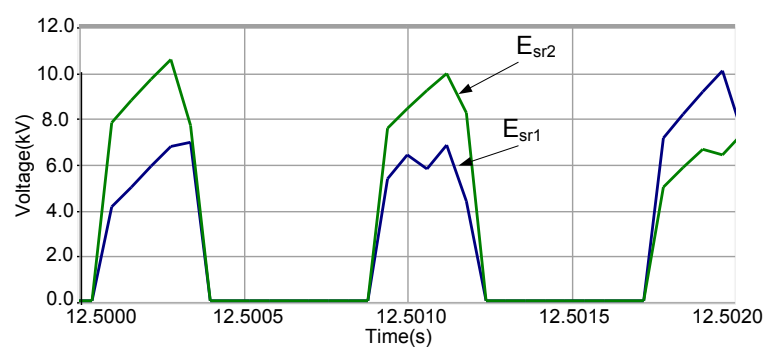

(c) Voltage stresses on the Switches $\mathrm{S}_{\mathrm{r} 1}$ and $\mathrm{S}_{\mathrm{r} 2}$ of the modified version of the WECS

Fig. 5 waveforms show the performance of the proposed convertesr.

\section{b. Low voltage ride-through (LVRT)}

This subsection investigates the fault ride-through capability of the proposed WECS. During LVRT, the dual CSI cannot deliver the active power produced by the wind turbine to the grid. This will create a significant power imbalance between the dual CSI ac and dc sides; thus, causes $\overline{I_{L_{-} r e f}}$ to increase to compensate the drop in the grid voltage. The current limiter implemented within the proposed control limits the reference current to $1.2 \mathrm{kA}$, to protect the power electronics devices from over current, see Fig. 2(a). During the LVRT, the wind turbine speed builds up, and the extra kinetic energy is stored in the large inertia of the wind turbine. Under extended period of voltage dip, the generator speed will keep increasing, and this will expose converter switches to overvoltage. To overcome this issue, a dc active crowbar (braking chopper $S_{c b 1}, S_{c b 2}$ and $R_{c b 1}, R_{c b 2}$ in Fig. 1(b)) is added to limit the wind turbine speed increase until the pitch angle controller takes action (progressively over 10 to $20 \mathrm{~s})$. The de active crowbar is activated when the generator speed is more than $10 \%$ of rated speed. During simulation the wind speed was set to $12.5 \mathrm{~m} / \mathrm{s}$, and at $t=5 \mathrm{~s}$, the grid voltage drops to $10 \%$ of its rated value for $140 \mathrm{~ms}$, and then recovers. This simulation scenario is selected to show the performance of the proposed WECS under LVRT. Fig. 6 shows waveforms that summarize the WECS overall performance. Fig. 6 (a) shows the generator speed, where during LVRT the generator speed increases but insufficient to activate the crowbar. Fig. 6(b) shows the grid phase ' $a$ ' voltage and current; where the proposed WECS delivers reactive current to the grid during LVRT. Fig. 6 (c) shows that the grid delivered power reduces to zero during LVRT and smoothly recovers when the fault is cleared. The energy stored during the grid fault is transferred to the grid when the 
fault is cleared. Fig. 6 (d) show that the $q$-component of the grid current increases to the rated value during LVRT, and decreases to zero after the grid fault.

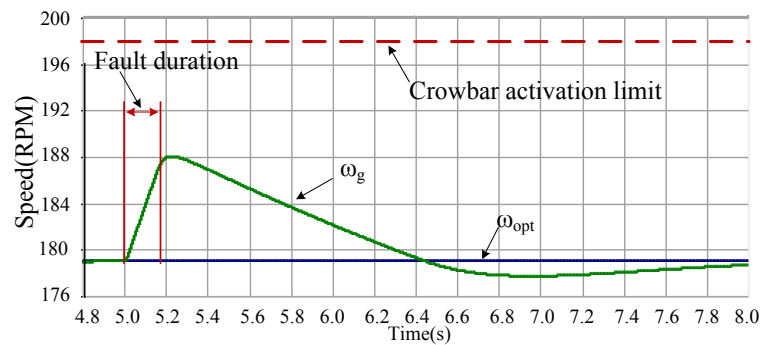

(a) Generator speed during grid fault and recovery.

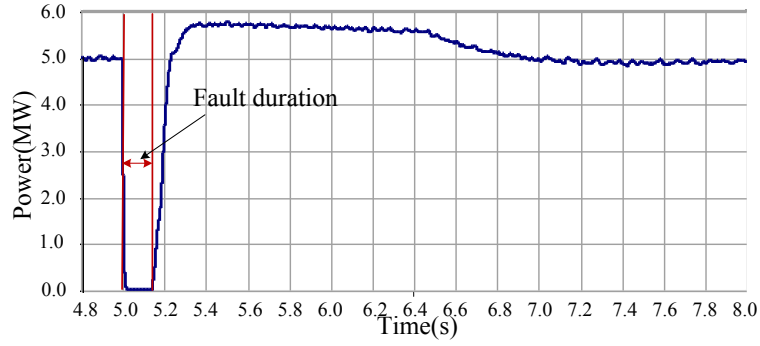

(c) Grid delivered power during grid fault and recovery. Fig. 6 Waveforms summarise the overall performance of the proposed WECS during a LVRT condition.

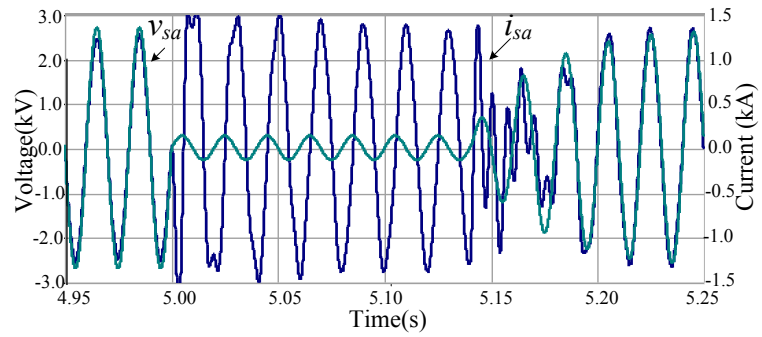

(b) Phase ' $a$ ' voltage and current during LVRT and recovery.

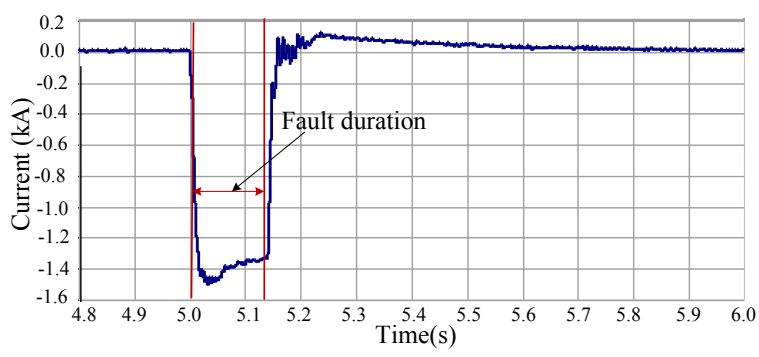

(d) Grid q-component current during grid fault and recovery

\section{Experimental Results}

The performance of the proposed WECS shown in Fig. 1(a) is experimentally evaluated, with different cases used to assess its dynamic performance Fig. 7(a) Shows the dual three-phase PMSG emulator, which consists of a three-phase synchronous generator connected to a phase-shift transformer. Fig. 7(b) shows the $2 \mathrm{kVA}$ experimental test rig. The experimental parameters are given in Table 2.The experimental test is at three different wind speeds; each lasting for $40 \mathrm{~s}$, with initial wind speeds at $6 \mathrm{~m} / \mathrm{s}$, which undergoes a step increase to $8 \mathrm{~m} / \mathrm{s}$ and then to $7 \mathrm{~m} / \mathrm{s}$. This sequence is repeated to enable examination of the dynamic performance and stability of the proposed system. The corresponding optimal generator speeds at each wind speed are $600 \mathrm{rpm}, 800 \mathrm{rpm}$ and 700 rpm respectively. Fig. 8 and Fig. 9 show experimental waveforms from the WECS. Fig. 8(a) shows the generator is able to track the optimal speed and produces the corresponding active power being delivered to the grid at the different wind speeds. The proposal speed controller forces the generator to run at the optimal speed with minimal transient and oscillations at different wind speed conditions. Also Fig. 8 (a) shows the active power delivered to the grid changes smoothly with minimum oscillation. Fig. 8(b) shows that the proposed speed control loop ensures soft started up. Fig. 8 (c) shows a snapshot of the output current injected into grid and phase ' $a$ ' voltage at $8 \mathrm{~m} / \mathrm{s}$ wind speed, where the grid current is sinusoidal, with nearly zero reactive power. Fig. 9 (a) shows a detailed view of the dc-link inductor current $I_{L}$, dual CSI input current $I_{i}$ and switch current $I_{s}$. From Fig. 9(a), when the switch $S_{r}$ is on, the dc-link inductor current rises and equals the switch current $I_{s}$, and 
the dual CSI input current $I_{i}$ equals zero, while when the switch is off the dc-link inductor current $I_{L}$ falls to the dual CSI input current $I_{i}$, and the switch current $I_{s}$ is zero. Fig. 9(b) show the dual CSI output currents ' $i_{a l}$ ' and ' $i_{a 2}$ ', where the dual CSI converters the input current $I_{i}$ to ac current.

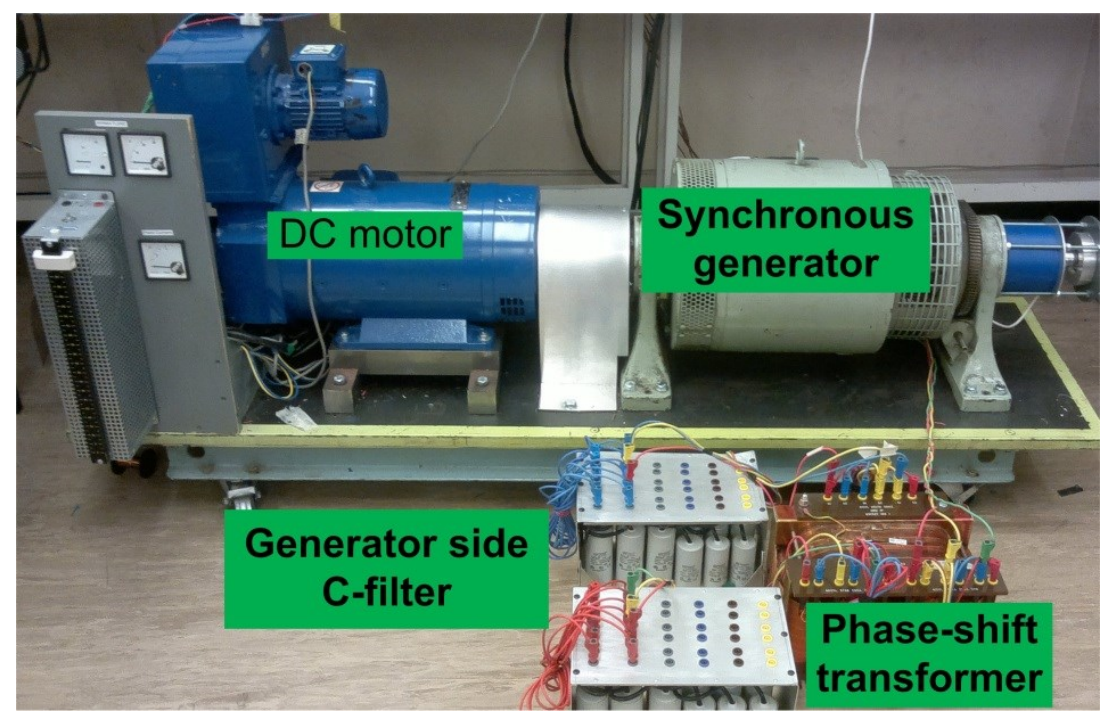

(a)Dual three-phase PMSG emulator

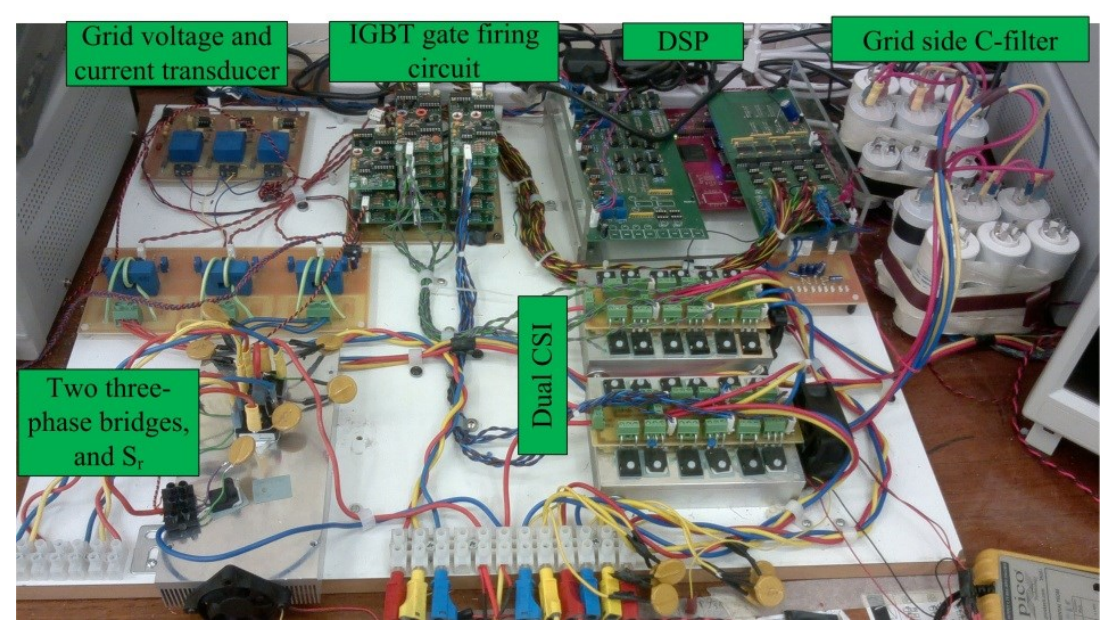

(b) Test rig.

Fig. 7 Experimental prototype. 


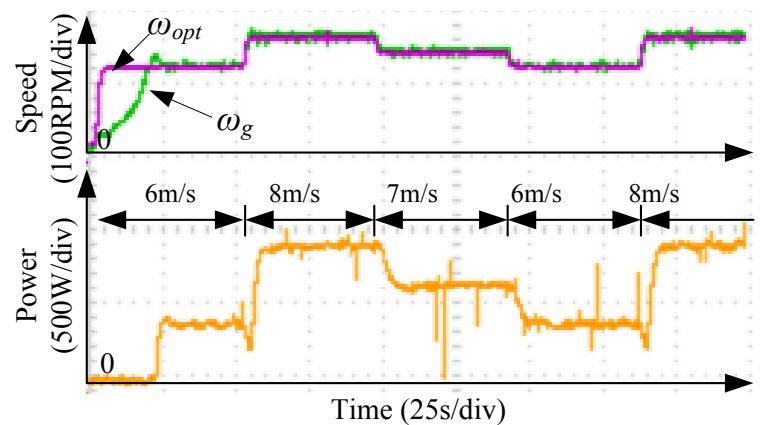

(a) Generator speed, optimal generator speed and grid output power during the proposed scenario.

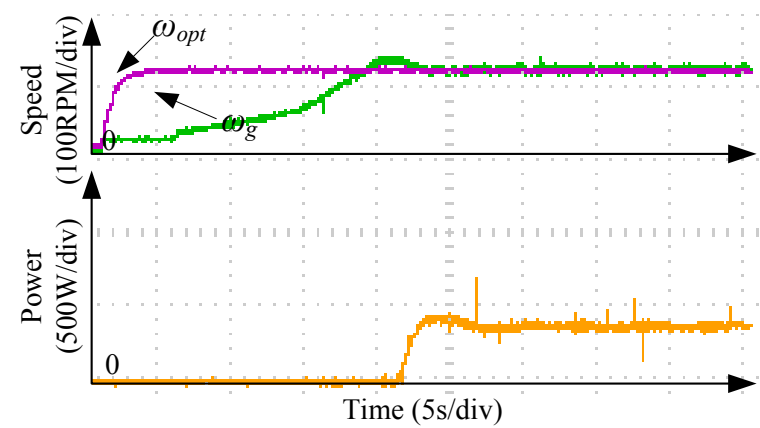

(b) Generator speed, optimal generator speed and grid output power during start-up.

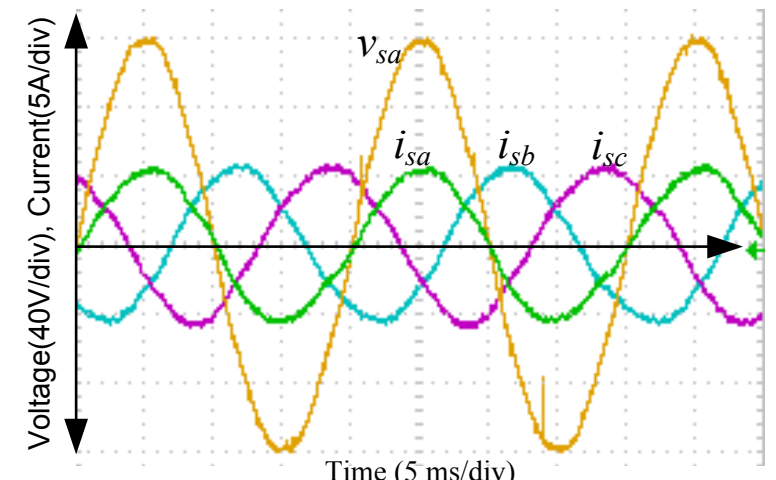

(c) Three phase grid currents and phase ' $a$ ' voltage, at $8 \mathrm{~m} / \mathrm{s}$.

Fig. 8 Waveforms showing the overall performance of the proposed WECS.

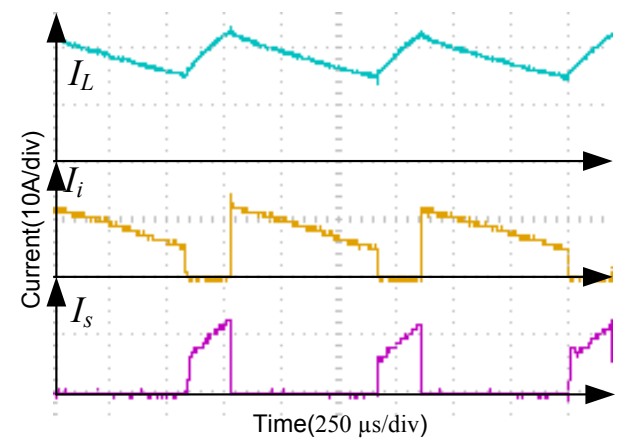

(a) dc-side inductor current $I_{L}$, switch current $I_{S}$, and CSI input current $I_{i}$ at $8 \mathrm{~m} / \mathrm{s}$ wind speed.

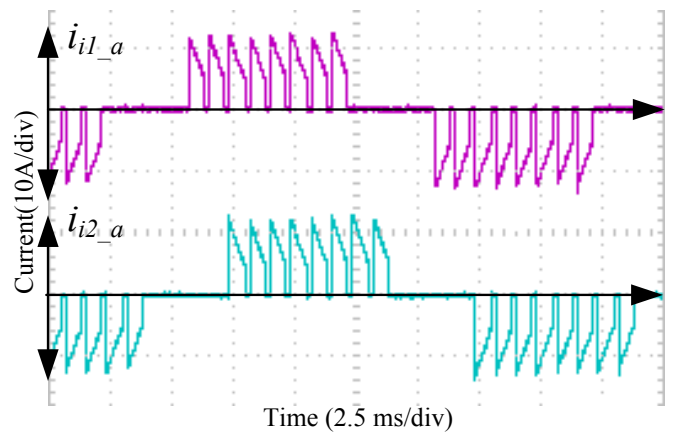

(b) Dual CSI phase output current ' $i_{i I_{-} a}$ ' and ' $i_{i 2 \_a}$ ' at $8 \mathrm{~m} / \mathrm{s}$.

Fig. 9 Waveforms analyse the dc-side inductance current, switch current, CSI input current, and dual CSI output current

Table 2 Experimental parameters

\begin{tabular}{|l|l|}
\hline \multicolumn{2}{|c|}{ Wind Turbine Parameters } \\
\hline Power at rated wind speed & $4.6 \mathrm{~kW}$ \\
\hline Cut-in wind speed & $4 \mathrm{~m} / \mathrm{s}$ \\
\hline Rated wind speed & $12.5 \mathrm{~m} / \mathrm{s}$ \\
\hline Rotor diameter & $3.2 \mathrm{~m}$ \\
\hline Rotor area & $8.04 \mathrm{~m}^{2}$ \\
\hline Gearbox ratio DC motor Parameters \\
\hline \multicolumn{2}{|c|}{$1: 2.07$} \\
\hline Rated armature voltgae & $460 \mathrm{~V}$ \\
\hline Rated speed & $1500 \mathrm{rpm}$ \\
\hline Rated current & $16 \mathrm{~A}$ \\
\hline Field current & $1.2 \mathrm{~A}$ \\
\hline Armature resistance & $2.5 \Omega$ \\
\hline Toque constant $\mathrm{K}_{\mathrm{m}}$ & 2.47 \\
\hline \multicolumn{2}{|c|}{ Synchronus machine parmeters } \\
\hline Rated speed & $1500 \mathrm{rpm}$ \\
\hline Rated voltgae & $400 \mathrm{~V}$ \\
\hline
\end{tabular}




\begin{tabular}{|l|l|}
\hline Rated current & $10 \mathrm{~A}$ \\
\hline Rated frequency & $50 \mathrm{~Hz}$ \\
\hline Number of poles & 4 \\
\hline Field current & $0.5 \mathrm{~A}$ \\
\hline Genrator voltgae constant $\mathrm{K}_{\mathrm{G}}$ & 2.5 \\
\hline armature restance & $1.2 \Omega$ \\
\hline armature inductance & $36 \mathrm{mH}$ \\
\hline \multicolumn{2}{|c|}{ Genrator side phase shift transformer parmeters } \\
\hline Rated power & $2 \mathrm{kVA}$ \\
\hline Primary rated voltge & $415 \mathrm{~V}(\Delta$ connection) \\
\hline Two secondary winding rated voltage & $415 \mathrm{~V}$ ( $\Delta$ connection) \\
\hline \multicolumn{2}{|c|}{$400 \mathrm{~V}$ (Y connection) } \\
\hline Genrator side Cfilter & $120 \mu \mathrm{F}$ (Y connection) \\
\hline dc-link inductance parameters \\
\hline Grid side C-filter & $5 \mathrm{mH}$ \\
\hline \multicolumn{2}{|c|}{ grid side phase shift transformer parmeters } \\
\hline Rated power & $2 \mathrm{kVA}$ \\
\hline Primary winding rated voltge & $415 \mathrm{~V}$ (Y connection) \\
\hline Two secondary winding rated voltage & $208 \mathrm{~V}$ (Y connection) \\
$208 \mathrm{~V}(\Delta$ connection) \\
\hline \multicolumn{2}{|c}{ CONCLU SIONS } \\
\hline
\end{tabular}

This paper proposed new dual three-phase BTB CSC and explored its application in multi-megawatt WECS.

The use of diode rectifiers with a phase-shift transformer or multi-phase machine as suggested in this paper at the input side, eliminates pulsating torque due to $5^{\text {th }}$ and $7^{\text {th }}$ harmonics. Besides power circuit and control systems simplicity, the proposed BTB converter offers zero switching losses in the grid side converter. Additionally, this paper investigated the possibility of extending the proposal WECS in order to effectively reduce the voltage stress on the switch $S_{r}$, by using dual converters. Simulation and experimental results show that proposed WECS can satisfy ride-through requirements and has good dynamic performance, with stable ac grid output voltage and current waveforms over a wide wind speed range.

\section{References}

[1] N. Gyawali, Y. Ohsawa, and O. Yamamoto, "Power management of double-fed induction generatorbased wind power system with integrated smart energy storage having superconducting magnetic energy storage/fuel-cell/electrolyser," Renewable Power Generation, IET, vol. 5, pp. 407-421, 2011.

[2] $\mathrm{H}$. Li and Z. Chen, "Overview of different wind generator systems and their comparisons," Renewable Power Generation, IET, vol. 2, pp. 123-138, 2008.

[3] E. Lepa, T. Thurnherr, and A. Faulstich, "Design and testing of a $7 \mathrm{MW}$ wind turbine medium voltage electrical drivetrain with medium speed permanent magnet synchronous generator," EWEA 2013 Europe's Premier Wind Energy Event, pp. 1-8, 2013.

[4] O. Alizadeh and A. Yazdani, "A Strategy for Real Power Control in a Direct-Drive PMSG-Based Wind Energy Conversion System," Power Delivery, IEEE Transactions on, vol. 28, pp. 1297-1305, 2013.

[5] J. M. Espi and J. Castello, "Wind Turbine Generation System With Optimized DC-Link Design and Control," Industrial Electronics, IEEE Transactions on, vol. 60, pp. 919-929, 2013.

[6] A. Uehara, A. Pratap, T. Goya, T. Senjyu, A. Yona, N. Urasaki, and T. Funabashi, "A Coordinated Control Method to Smooth Wind Power Fluctuations of a PMSG-Based WECS," Energy Conversion, IEEE Transactions on, vol. 26, pp. 550-558, 2011.

[7] G. O. Suvire and P. E. Mercado, "Combined control of a distribution static synchronous compensator/flywheel energy storage system for wind energy applications," Generation, Transmission \& Distribution, IET, vol. 6, pp. 483-492, 2012. 
[8] X. Yuanye, K. H. Ahmed, and B. W. Williams, "Wind Turbine Power Coefficient Analysis of a New Maximum Power Point Tracking Technique," Industrial Electronics, IEEE Transactions on, vol. 60, pp. 1122-1132, 2013.

[9] M. Singh, V. Khadkikar, and A. Chandra, "Grid synchronisation with harmonics and reactive power compensation capability of a permanent magnet synchronous generator-based variable speed wind energy conversion system," Power Electronics, IET, vol. 4, pp. 122-130, 2011.

[10] Z. Shao, T. King-Jet, D. M. Vilathgamuwa, N. Trong Duy, and W. Xiao-Yu, "Design of a Robust Grid Interface System for PMSG-Based Wind Turbine Generators," Industrial Electronics, IEEE Transactions on, vol. 58, pp. 316-328, 2011.

[11] L. Jun, S. Bhattacharya, and A. Q. Huang, "A New Nine-Level Active NPC (ANPC) Converter for Grid Connection of Large Wind Turbines for Distributed Generation," Power Electronics, IEEE Transactions on, vol. 26, pp. 961-972, 2011.

[12] N. P. W. Strachan and D. Jovcic, "Stability of a Variable-Speed Permanent Magnet Wind Generator With Weak AC Grids," Power Delivery, IEEE Transactions on, vol. 25, pp. 2779-2788, 2010.

[13] E. Levi, "Multiphase Electric Machines for Variable-Speed Applications," Industrial Electronics, IEEE Transactions on, vol. 55, pp. 1893-1909, 2008.

[14] L. Parsa, "On advantages of multi-phase machines," in Industrial Electronics Society, 2005. IECON 2005. 31st Annual Conference of IEEE, 2005, p. 6 pp.

[15] A. A. Nahome, R. Zaimeddine, L. Bing, and T. Undeland, "Vector control of direct drive six phase permanent magnet synchronous generators," in PowerTech, 2011 IEEE Trondheim, 2011, pp. 1-7.

[16] S. Kato, Y. Inui, M. Michihira, and A. Tsuyoshi, "Low-Cost Wind Generator System with a Permanent Magnet Synchronous Generator and Diode Rectifiers," in ICREPQ'06 International Conference on Renewable Energy and Power Quality, 2006.

[17] H. Weihao, W. Yue, S. Xianwen, and W. Zhaoan, "A Novel Sensorless Unity Power Factor Control Method for Six-phase PMSG in Direct Drive Wind Energy Conversion Systems," in Applied Power Electronics Conference and Exposition, 2009. APEC 2009. Twenty-Fourth Annual IEEE, 2009, pp. 744-749.

[18] M. J. Duran, S. Kouro, W. Bin, E. Levi, F. Barrero, and S. Alepuz, "Six-phase PMSG wind energy conversion system based on medium-voltage multilevel converter," in Power Electronics and Applications (EPE 2011), Proceedings of the 2011-14th European Conference on, 2011, pp. 1-10.

[19] L. Jiawen, N. Heng, and S. Yipeng, "Dual stator windings PMSG fed by half-controlled converters for wind power application," in Electrical Machines and Systems (ICEMS), 2011 International Conference on, 2011, pp. 1-6.

[20] I. Abdelsalam, G. P. Adam, D. Holliday, and B. W. Williams, "Assessment of a wind energy conversion system based on a six-phase permanent magnet synchronous generator with a twelve-pulse PWM current source converter," in ECCE Asia Downunder (ECCE Asia), IEEE, 2013, pp. 849-854.

[21] I. Abdelsalam, G. P. Adam, D. Holliday, and B. W. Williams, "New back-to-back current source converter with soft start-up and shutdown capabilities," in Power Electronics, Machines and Drives (PEMD 2014), 7th IET International Conference on, 2014, pp. 1-5.

[22] I. Abdelsalam, G. P. Adam, D. Holliday, and B. W. Williams, "Modified back-to-back current source converter and its application to wind energy conversion systems," IET Power Electronics, vol. 8, pp. 103-111, 2014.

[23] I. Abdelsalam, G. P. Adam, D. Holliday, and B. W. Williams, "Single-stage ac-dc buck-boost converter for medium-voltage high-power applications," Renewable Power Generation, IET, vol. 10, pp. 184-193, 2016.

[24] D. O'Kelley and S. Simmons, Introduction to generalized electrical machine theory: McGraw-Hill, 1968.

[25] I. Abdelsalam, G. P. Adam, D. Holliday, and B. W. Williams, "Three-phase ac-dc buck-boost converter with a reduced number of switches," Renewable Power Generation, IET, vol. 9, pp. 494-502, 2015.

[26] D. G. Holmes and T. A. Lipo, Pulse Width Modulation for Power Converters: Principles and Practice: John Wiley \& Sons, 2003. 